\title{
Strategi pemasaran dalam meningkatkan penjualan hunian kamar di devin sky hotel seminyak
}

\author{
I Gede Suastawa Arimbawa1), Ida Bagus Ketut Astina' ${ }^{2}$, I Gusti Ngurah Widyatmaja ${ }^{3)}$ \\ DIV Pariwisata, Fakultas Pariwisata, Universitas Udayana, \\ J1. Dr. R Goris No. 7, Denpasar, 80114 Telp/Fax : 0361_223798 \\ Email : kububerdebu@gmail.com
}

\begin{abstract}
Abstrak
Penelitian ini di das arioleh rendahnya tingkat penjualan kamar di Devin Sky hotel Seminyakdis aat tingkat kunjungan wis atawan meningkat. Selain itu ju ga dilatar belakangi oleh perluny a strategi pemasaran yangbanu dan signifikan dalam proses pers aing an pas ar antar kompetitor untuk mendapatkan tingkat penjualankamar yang lebih baik dari sebelumny a deng an memaks imalkan baik dari kondisi internal maupun eks ternal hotel yang berpengaruh dalamproses penjualan kamar. Tujuan dari penelitian ini adalah untukmengetahuikondisi internal maupun eks pternal hotel yang harus ditingkatkan dalamrangka membangun strategipemasaranyang tepat dan signifikan dalamuntuk meningkatkan penjualan tingkat hunian kamar hotel. Pengumpulandatayang dilakukan didalamproses penelitian ini menggunakan metode observasi, dokumentasi, kuesionerdantinjauan pustaka, dengan lebih menitik beratkan pada penyebaran kuesioner yang didalamnya terdapat beberapa indikator sebagai pertanyaan. Kemudian dianalis is menggunakan skala likert dan analisis SWOT.Hasilyang diperoleh adalah secara umumrata - rata kes eluruhan pers epsi res ponden memperoleh has ilyangtinggiyakni sebesar 3,36. Hal ini menunjukan indikator dalampenyataan ters ebut menjawab bahwa pelangganmerasakan kualitas pemas aran yang cukup baik dari segi lingkungan internal dan eks ternal. Berdasarkan hasil analis is SWOT, terdapat beberapa s trategi yang dapat diterapkan untuk mengembangkan startegi baru yaitu strategi SOdengan Menambah promosi produk sesuaidengan selera dan kebutuhan wis atawan serta meningkatkan promosi online. Strategi WO dengan lebih memfokuskan dan memprioritas kan segmentasi pas ar Asia.Serta strategi ST yaitu dengan penggunaan kebijakan-kebijakan promosi yang menarik wisatawan,sepertipemberian potong an harga dan membuat paket penjualan tertentu dengan harga yang lebih rendah namum kompetitif
\end{abstract}

Kata kunci : Strategi pemasaran, SWOT, Hunian Kamar

\begin{abstract}
This research is motivated by the low level of room sales in De Vins Sky Semin yak hotel swhentouristarrival increase. In addition, it was also motivated by the need for a new marketing strategyandsignificantmarketing strategy in the process ofmark et competition among competitors to get a better than previouslevelofroom sales by maximizing both the internal and external conditions of the hotel that influencetheprocess ofselling rooms. The purpose of this research is to find out the internal and external condition softhehotel thatmustbe improved in order to build a proper and significant marketing strategy in order to increasethesalesofhotel room occupancy rates. Data collection carried out in this research process usesobservation,documentation, questionnaires and literature reviews, with more emphasis on distributing questionnairesinwhich thereare several indicators as questions. Then analyzed using a Likert scale and SWOT analysis.Theresultsobtained are generally the average overall perception of the respondents obtained a high yieldof3.36.Thisshowsthat the indicators in the statement answer that customers feel that the quality ofmarketing is sufficientbothin terms of internal and external environment. Based on the results of the SWOT analysis, there are several strategies that can be applied to develop a new strategy, namely the SO strategy by increasing product promotion according to the tastes and needs of tourists and increasing online promotion. The WOstrategy focuses more and prioritizes the segmentation of the Asian market. As well as the ST strategy, namelybythe use of promotional policies that attract tourists, such as giving discounts and makingcertainsalespackages at lower prices but competitive
\end{abstract}

Keywords: Marketing strategy, SWOT, Room Occupancy 


\section{PENDAHULUAN}

Semakin pesatnya perkembangan pariwisata belakangan ini memang sangat menjanjikan bagi para pelaku industri pariwisata di Indonesia terlebih lagi Bali. Bali dikenal sebagai pulau yang memiliki daya tarik wisata yang memukau bagi hampir keseluruhan wis ataw an yang berkunjung ke Bali. Pulau Bali memang masih menjadi tujuan wisata favorit di Indonesia. Perkembangan jumlah kunjungan wisatawan mancanegara dan domestik ke Bali dapat dilihat pada Tabel 1.1 sebagai berikut:

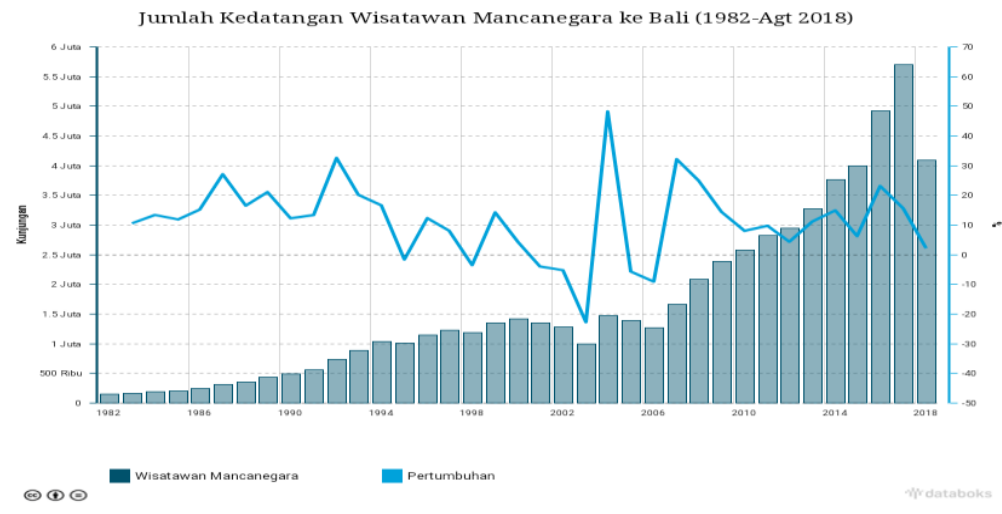

Gambar 1. Jumlah Kedatangan W isatawan BaliTahun 1982-2018

Jika dilihat dari gambar, jumlah pertumbuhan wisatawan yang datang ke Bali dari tahun 2011 sampai tahun 2015 rata-rata pertumbuhan pertahunnya sebanyak 8,78 persen. Pada tahun 2011 merupakan pertumbuhan tertinggi mencapai 18,10 persen. Penurunan jumlah wisatawan sempat terjadi pada tahun 2014 sebesar 0,94 hal ini dikarenakan meningkatnya tingkat kriminalitas, kemacetan, kotor karena sampah dan menurunnya nilai rupiah. Tetapi hal ini tidak berpengaruh kepada wisatawan mancanegara yang tetap mengalami peningkatan kunjungan setiap tahunnya. Wisataw an mancanegara merasa Bali adalah salah satu destinasi terbaik di dunia dikarenakan Bali memiliki keindahan pantai dan pariwisata budaya yang unik.

Berdasarkan latar belakang yang tersebut maka yang menjadi pokok permasalah dalam penelitian ini adalah bagaimana kondisi lingkungan internal dan eksternal di Devin Sky Hotel Seminyak serta bagaimana strategi pemasaran yang diterapkan oleh Devin Sky Hotel Seminyak dalam meningkatkan tingkat penjualan kamar. Berdasarkan pada rumusan masalah tersebut, adapun tujuan dari penelitian ini adalah untuk mengetahui kondisi lingkungan internal dan eksternal di Devin Sky Hotel Seminyak dan mengetahui strategi pemasaran yang tepat sehingga dapat digunakan untuk meningkatkan tingkat penjualan kamar Devin Sky Hotel Seminyak.

Tinjauan hasil penelitian sebelumnya yang dimaksud adalah kajian terhadap hasil karya tulis yang relevan dengan penelitian ini. Berikut adalah telaah penelitian yang digunakan sebagai acuan dalam penelitian ini.

Penelitian sebelumnya dipilih sebagai pedoman atau acuan dalam penelitian ini. Dalam penelitian ini akan diuraikan hasil penelitian sebelumnya, diantaranya sebagai berikut: Penelitian oleh Dwiki (2015) “ Strategi Pemasaran Pada The Samaya Ubud Bali Resort di Kabupaten Gianyar Bali “. Penelitian yang dilakukan bertujuan untuk mengetahui faktor internal dan ekternal, untuk menganalisis strategi pemasaran yang dapat diterapkan dan untuk menyusun program-program pemasaran yang dapat diterapkan di The Samaya Ubud Bali. Jenis data yang digunakan adalah data kualitatif dan kuantitatif. Teknik pengumpulan data dilakukan dengan observasi, wawancara terstruktur, studi kepustakaan dan dokumentasi. Teknik analisi data yang digunakan adalah deskriftif kualitatif yang dipadukan dengan analisis SWOT. Penelitian yang kedua dilakukan Wibisono (2010), yang berjudul "Penerapan Analisis SWOT Dalam Strategi Pemasaran di The Patra Bali Resort \& Villas - Tuban - Bali". Penerapan analisis SWOT merupakan teknik analisis data yang dipergunakan, dimana dalam laporan ini dijelaskan kekuatan, kelemahan, peluang dan tantangan dalam kegiatan pemasaran di Patra Bali Resort \& Villas. 
Analisis SWOT lebih di analisis secara rinci. Analisis SWOT inilah yang menjadi pedoman dalam penyusunan penelitian ini. Adapun hasil serta kesimpulan dari laporan ini bahwa strategi pemasaran yang telah diterapkan oleh Patra Jasa Bali Resort \& Villas dilihat dari analisis SWOT, bahwa pemasaran dalam penjualan kamar telah baik dimana fluktuasi hunian yang tidak pernah mengalami penurunan secara drastis, dimana market segmen atau pangsa pasar wisatawan utama adalah China-Taiwan, dan Australia pada posisi kedua. Penelitian yang ketiga dilakukan Kayoga dengan judul "Strategi Pemasaran Pada Hotel Sanur Paradise Plaza di Kawasan Wisata Sanur Bali". Pada penelitian ini menggunakan analisis SWOT serta bauran pemasaran, dan teknik pengumpulan data dipergunakan observasi, wawancara mendalam dan dokumentasi. Hasil dari penelitian ini adalah grafik SWOT serta saran yang diberikan kepada manajemen hotel antara lain meningkatkan kualitas produk dan melakukan upaya perbaikan pada segmenting, targeting dan positioning.

Berdasarkan pembahasan diatas diperoleh letak persamaan pada penelitian tersebut adalah sama-sama membahas tentang strategi pemasaran serta menggunakan analisis SWOT didalamnya. Sedangkan yang membedakan adalah objek yang diteliti serta lokasi penelitian. Manfaat yang diambil dari penilitian tersebut adalah dapat dijadikan acuan atau kerangka berpikir untuk merancang penelitian ini. Mengingat kerangka dasar dari masing-masing penelitian tersebut dapat dikatakan sama dengan kerangka penelitian penulis hanya saja dibedakan oleh lokasi, penentuan sampel serta objek yang diteliti.

\section{METODE PENELTIAN}

Penelitian ini menggunakan teknik pengumpulan data dengan observasi, wawancara, dokumentasi,kuesioner dan studi kepustakaan. Teknik penentuan informan adalah purposive sampling. Sampel yang digunakan adalah 95 orang wisataw an yang pernah menginap di Devin Sky Hotel. Analisis data yang digunakan adalah deskriptif kualitatif dan kuantitatif yang ditunjang dengan skala likert yang di padukan dengan analisis SWOT.

\section{HASIL DAN PEMBAHASAN}

Devin Sky Hotel Seminyak pada awalnya merupakan Hotel Golden Tulip Devins Seminyak yang memutuskan untuk melepaskan diri dari Louvre Hotels Group yang merupakan induk perusahaan dari Premiere Class, Campanile, Kyriad dan Kyriad Prestige. Resmi berpisah setahun lalu pada tanggal 19 Januari 2018 dan kini berdiri sebagai hotel independent. Tidak terdapat banyak perubahan yang signifikan dalam proses perubahan hotel tersebut, hanya pada logo, nama dan sedikit pada design. Mengenai bentuk, jumlah kamar, fasilitas, sistem organisasi masih tetap sama dengan bentuk sebelumnya. Devin Sky Hotel Seminyak yang berlokasi di Jln. Petitenget - Komplek Villa Kendal no. 35 Seminyak, Badung-Bali. Meskipun hotel ini terbilang hotel yang baru, saat ini sudah memiliki jumlah kamar sebanyak 108 kamar dengan beberapa tipe kamar yang berbeda dengan dilengkapi berbagai fasilitas penunjang untuk tamu. adapun tipe kamarnya yaitu: Superior Room, Deluxe Room, Premier Jacuzzi, Premier Pool, dan Penthhouse Suite Room.

Dalam penelitian ini penulis menyebarkan kuisioner kepada 95 orang pelanggan Devin Sky Hotel Seminyak, yang dilaksanakan dari tanggal 3 Desember 2018 sampai tanggal 22 Maret 2019 setiap hari kerja, dimana penulis terlibat langsung dalam proses pengisian kuisioner. Berdasarkan hasil penelitian, didapat sebuah gambaran tentang karakteristik responden. Uraian tentang karakteristik responden berdasarkan, kew arganegaraan, jenis kelamin, usia, pendidikan terakhir, dan pekerjaan responden. Distribusi responden pada penelitian ini diuraikan sebagai berikut:

Profil kewarganegaraan digunakan untuk mengetahui proporsi pelanggan Devin Sky Hotel Seminyak berdasarkan asal negaranya. Data responden yang diperoleh dari hasil kuesioner yang telah disebar berdasarkan kew arganegaraan dipaparkan dalam Tabel 3.3

Tabel 1. Karakteristik Res ponden Berdasarkan Kewarg anegaraan

\begin{tabular}{|l|c|c|}
\hline \multicolumn{1}{|c|}{ Kewarganegaraan } & Jumlah Responden (Orang) & Persentase (\%) \\
\hline Australia & 30 & 31,58 \\
\hline Indonesia & 16 & 16,84 \\
\hline
\end{tabular}




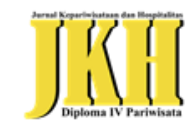

JURNAL KEPARIWISATAAN DAN HOSPITALITAS Vol. 4, No. 1, April 2020.

\begin{tabular}{|l|c|c|} 
China & 8 & 8,42 \\
\hline Portugal & 7 & 7,37 \\
\hline Belanda & 7 & 7,37 \\
\hline Rusia & 6 & 6,32 \\
\hline Newzealand & 3 & 3,16 \\
\hline Malaysia & 3 & 3,16 \\
\hline Filipina & 2 & 2,11 \\
\hline Singapura & 2 & 2,11 \\
\hline Irlandia & 2 & 2,11 \\
\hline Finlandia & 2 & 2,11 \\
\hline Chille & 1 & 1,05 \\
\hline Haiti & 1 & 1,05 \\
\hline India & 1 & 1,05 \\
\hline Kanada & 1 & 1,05 \\
\hline Mozambik & 1 & 1,05 \\
\hline Romania & 1 & 1,05 \\
\hline Bulgaria & 1 & 1,05 \\
\hline & 95 & 100 \\
\hline
\end{tabular}

Sumber: Data primer diolah (Lampiran 4), 2019

Tabel 1. menunjukkan bahwa responden yang menjadi pelanggan Devin Sky Hotel Seminyak di Bali dalam penelitian ini berasal dari 19 negara yaitu Australia, Indonesia, Cina, Portugal, Belanda, Rusia, Newzealand, Malaysia, Filipina, Singapura, Irlandia, Finlandia, Chille, Haiti, India, Kanada, Mozambik, Romania dan Bulgaria. Persentase jumlah responden yang menjadi pelanggan Devin Sky Hotel Seminyak di Bali dalam penelitian ini di dominasi oleh wisatawan warga negara Australia dengan jumlah sebnyak 30 orang, kemudian domestik berjumlah sebanyak 16 orang, China sebanyak 8 orang, Portugal dan Belanda masing-masing berjumlah 7 orang, Rusia dengan jumlah 6 orang, Nezealand dan Malaysia dengan jumlah 3 orang, tamu yang berasal dari Filipina, Singapura, Irlandia, dan Finlandia dengan jumlah 2 orang, sedangkan sisanya yang berasal dari Chille, Haiti, India, Kanada, Mozambik, Romania dan Bulgaria berjumlah 1 orang.

Profil jenis kelamin digunakan untuk mengetahui proporsi responden laki-laki dan perempuan. Data responden yang diperoleh dari hasil kuesioner yang telah disebar berdasarkan jenis kelamin dipaparkan dalam Tabel 2.

Tabel2. Karakteristik Responden Berdasarkan Jenis Kelamin.

\begin{tabular}{|l|c|c|}
\hline \multicolumn{1}{|c|}{ Jenis Kelamin } & Jumlah Responden (Orang) & Persentase (\%) \\
\hline Laki-laki & 48 & 50,53 \\
\hline Perempuan & 47 & 49,47 \\
\hline Jumlah & 95 & 100 \\
\hline
\end{tabular}

Sumber: Data primer diolah (Lampiran 4), 2019

Tabel 2. menunjukkan bahwa persentase jumlah responden laki-laki adalah sebesar 50,53 persen dan perempuan sebanyak 49,47 persen. Hal ini menunjukkan bahwa sebagian besar responden yang menjadi pelanggan Devin Sky Hotel Seminyak di Bali dalam penelitian ini berimbang antara laki-laki dan perempuan.

Profil terkait usia menunjukkan kelompok umur pelanggan Devin Sky Hotel Seminyak. Data responden yang diperoleh dari hasil kuesioner yang telah disebar berdasarkan usia dipaparkan dalam Tabel 3 berikut. 
Tabel3. Karakteris tik Responden Berdasarkan Usia.

\begin{tabular}{|c|c|c|}
\hline Usia & Jumlah Responden (Orang) & Persentase (\%) \\
\hline 11- 20 Tahun & 3 & 3.16 \\
\hline $21-30$ Tahun & 66 & 69.47 \\
\hline $31-40$ Tahun & 18 & 18.95 \\
\hline $41-50$ Tahun & 6 & 6.32 \\
\hline$>50$ Tahun & 2 & 2.11 \\
\hline Jumlah & 95 & 100 \\
\hline
\end{tabular}

Sumber: Data primer diolah (Lampiran 4), 2019

Tabel 3. menunjukkan bahwa responden yang berusia 11 sampai 20 tahun adalah sebanyak 3 orang. Responden yang berusia 21 sampai 30 tahun tahun adalah sebanyak 66 orang. Responden yang berusia 31-40 tahun adalah sebanyak 18 orang. Responden yang berusia 41-50 tahun adalah sebanyak 6 orang dan responden yang berusia lebih dari 50 tahun sebanyak 2 orang. Hal ini menunjukkan bahwa responden yang telah berlangganan dengan Devin Sky Hotel Seminyak di Bali dominan adalah yang berusia 21 sampai dengan 30 tahun dengan persentase sebesar 69,47 persen.

Profil jenjang pendidikan merupakan indikator untuk mengetahui tingkat pendidikan akhir dari pelanggan Devin Sky Hotel Seminyak yang berpartisipasi dalam pengisian kuisioner. Data responden yang diperoleh dari hasil kuesioner yang telah disebar berdasarkan pendidikan terakhir dipaparkan dalam Tabel 4. berikut.

Tabel4. Karakteris tik Responden Berdasarkan Pendidikan

\begin{tabular}{|c|c|c|}
\hline Pendidikan Terakhir & Jumlah Responden (Orang) & Persentase \\
\hline SMA & 18 & 18,95 \\
\hline Diploma & 30 & 31,58 \\
\hline S1 & 32 & 33,68 \\
\hline S2 & 1 & 1,05 \\
\hline Doktoral & 0 & 0,00 \\
\hline Tidak menjawab & 14 & 14,74 \\
\hline Jumlah & 95 & 100 \\
\hline
\end{tabular}

Sumber : Data primer diolah (Lampiran 4), 2019

Tabel 4 menunjukkan bahwa responden yang memiliki pendidikan terakhir SMA (high school) adalah sebanyak 18 orang. Responden yang memiliki pendidikan terakhir Diploma adalah sebanyak 30 orang. Responden yang lulusan Sarjana (S1) adalah sebanyak 32 orang. Responden yang lulusan Pasca Sarjana sejumlah 1 orang, lalu tidak ada responden dengan gelar Doctoral dan sebanyak 14 orang sisanya tidak menjawab pertanyaan. Hal ini menunjukkan pendidikan terakhir responden yang berlanggan dengan Devin Sky Hotel Seminyak di Bali paling dominan adalah wisataw an yang lulusan Sarjana yakni sebanyak 33,68 persen.

Profil pekerjaan merupakan indikator untuk mengetahui pekerjaan responden yang berlanggan dengan Devin Sky Hotel Seminyak. Data responden yang diperoleh dari hasil kuesioner yang telah disebar berdasarkan status pekerjaan dipaparkan dalam Tabel 4.6.

Tabel 5. Karakteris tik Res ponden Berdasarkan Pekerjaan

\begin{tabular}{|l|c|c|}
\hline \multicolumn{1}{|c|}{ Pekerjaan } & $\begin{array}{c}\text { Jumlah Responden } \\
\text { (Orang) }\end{array}$ & Persentase (\%) \\
\hline Belum Bekerja (Unemployee) & 3 & 3,16 \\
\hline Pegawai Negeri(Government Employee) & 8 & 8,42 \\
\hline Pegawai Swasta (Private Employee) & 62 & 65,26 \\
\hline
\end{tabular}




\begin{tabular}{|c|c|c|} 
Pengusaha (Entrepreneur) & 14 & 14,74 \\
\hline Lainnya (Other) & 8 & 8,42 \\
\hline Jumlah & 95 & 100 \\
\hline
\end{tabular}

Sumber : Data primer diolah, 2019

Tabel 6. menunjukkan bahw a responden yang belum bekerja (unemployee) adalah sebanyak 3 orang. Responden yang bekerja sebagai pegaw ai negeri sebanyak 8 orang. Responden yang bekerja sebagai pegawai swasta sebanyak 62 orang. Responden yang berstatus pengusaha adalah sebanyak 14 orang, dan sisanya sebanyak 8 orang memiliki pekerjaan lainnya. Hal ini menunjukkan bahwa responden yang menjadi pelanggan Devin Sky Hotel Seminyak di Bali paling dominan adalah wisataw an yang status pekerjaannya sebagai pegaw ai swasta (private employee) yaitu sebesar 65,26 persen dari 95.

Hasil Deskripsi Responden

Tabel 7. Deskripsi Persepsi Res ponden

\begin{tabular}{|c|c|c|c|c|c|c|c|c|c|}
\hline \multirow{2}{*}{ No } & \multirow{2}{*}{ Pernyataan } & \multicolumn{5}{|c|}{ Proporsi Persepsi Responden (\%) } & \multirow{2}{*}{$\begin{array}{l}\text { Total } \\
\text { Skor } \\
\end{array}$} & \multirow{2}{*}{$\begin{array}{l}\text { Rata- } \\
\text { Rata } \\
\end{array}$} & \multirow{2}{*}{ Kriteria } \\
\hline & & 1 & 2 & 3 & 4 & 5 & & & \\
\hline 1 & $\begin{array}{l}\text { Penempatan bangunan yang } \\
\text { strategis \& private }\end{array}$ & 0 & 2 & 54 & 34 & 5 & 327 & 3.44 & Baik \\
\hline 2 & Wis atawan muda \& lifestyle & 0 & 1 & 41 & 47 & 6 & 343 & 3.61 & Baik \\
\hline 3 & $\begin{array}{l}\text { Segmentasi wis atawan } \\
\text { Australia \& eropa }\end{array}$ & 0 & 1 & 36 & 42 & 16 & 358 & 3.77 & Baik \\
\hline 4 & Rooftop pool & 0 & 0 & 25 & 34 & 36 & 391 & 4.12 & Baik \\
\hline 5 & Spa aquatonic & 0 & 2 & 19 & 49 & 25 & 382 & 4.02 & Baik \\
\hline 6 & Staff hotel & 0 & 1 & 35 & 49 & 10 & 353 & 3.72 & Baik \\
\hline 7 & $\begin{array}{l}\text { Kondisidari produkyg } \\
\text { ditawarkan }\end{array}$ & 0 & 4 & 36 & 44 & 11 & 347 & 3.65 & Baik \\
\hline 8 & $\begin{array}{l}\text { Pelayanan yg dilakukan } \\
\text { karyawan }\end{array}$ & 0 & 1 & 49 & 38 & 7 & 336 & 3.54 & Baik \\
\hline 9 & Restaurat\& bar & 0 & 2 & 38 & 48 & 7 & 345 & 3.63 & Baik \\
\hline 10 & $\begin{array}{l}\text { Kualitas produk yg } \\
\text { ditawarkan }\end{array}$ & 0 & 3 & 46 & 40 & 6 & 334 & 3.52 & Baik \\
\hline 11 & Kamar & 0 & 1 & 34 & 57 & 3 & 347 & 3.65 & Baik \\
\hline 12 & $\begin{array}{l}\text { International standarlocal } \\
\text { flavour }\end{array}$ & 0 & 4 & 55 & 34 & 2 & 319 & 3.36 & Cukup \\
\hline 13 & Online promotions & 1 & 5 & 52 & 35 & 2 & 317 & 3.34 & Cukup \\
\hline 14 & Akses menuju ke hotel & 0 & 0 & 64 & 30 & 1 & 317 & 3.34 & Cukup \\
\hline 15 & Meeting room & 3 & 9 & 51 & 31 & 1 & 303 & 3.19 & Cukup \\
\hline 16 & Offline promotions & 0 & 7 & 64 & 24 & 0 & 302 & 3.18 & Cukup \\
\hline 17 & $\begin{array}{l}\text { Kenyamanan dalam } \\
\text { menggunakan produk }\end{array}$ & 0 & 3 & 63 & 28 & 1 & 312 & 3.28 & Cukup \\
\hline 18 & $\begin{array}{l}\text { Menjalin kerjas ama dengan } \\
\text { perusahaan \& pemerintah }\end{array}$ & 1 & 6 & 58 & 28 & 2 & 309 & 3.25 & Cukup \\
\hline 19 & $\begin{array}{l}\text { Harga produk yang } \\
\text { ditawarkan }\end{array}$ & 0 & 7 & 65 & 22 & 1 & 302 & 3.18 & Cukup \\
\hline 20 & Manfaat produk & 0 & 4 & 75 & 16 & 0 & 297 & 3.13 & Cukup \\
\hline 21 & $\begin{array}{l}\text { Penigkatan jumlah kunjungan } \\
\text { wisatawan }\end{array}$ & 0 & 4 & 61 & 29 & 1 & 312 & 3.28 & Cukup \\
\hline 22 & Situasibudaya & 0 & 10 & 55 & 24 & 6 & 311 & 3.27 & Cukup \\
\hline
\end{tabular}




\begin{tabular}{|r|l|c|c|c|c|c|c|c|c|}
\hline 23 & Kemajuan teknologi & 0 & 4 & 68 & 21 & 2 & 306 & 3.22 & Cukup \\
\hline 24 & Pertumbuhan ekonomi dunia & 0 & 14 & 62 & 18 & 1 & 291 & 3.06 & Cukup \\
\hline 25 & $\begin{array}{l}\text { Kekuatan travelagent dalam } \\
\text { mendatangkan tamu }\end{array}$ & 0 & 15 & 61 & 18 & 1 & 290 & 3.05 & Cukup \\
\hline 26 & Situasipolitik dalam negeri & 2 & 15 & 63 & 14 & 1 & 282 & 2.97 & Cukup \\
\hline 27 & $\begin{array}{l}\text { Potensimasuknya pesaing } \\
\text { baru }\end{array}$ & 1 & 13 & 67 & 14 & 0 & 284 & 2.99 & Cukup \\
\hline 28 & $\begin{array}{l}\text { Situasi keamanan yang tidak } \\
\text { menentu }\end{array}$ & 0 & 15 & 64 & 15 & 1 & 287 & 3.02 & Cukup \\
\hline 29 & Persaingan antar hotel & 1 & 13 & 59 & 22 & 0 & 292 & 3.07 & Cukup \\
\hline 30 & Daya tawar konsumen & 1 & 10 & 69 & 15 & 0 & 288 & 3.03 & Cukup \\
\hline \multicolumn{6}{|c|}{ Rata-rata keseluruhan persepsi responden } & & 9584 & 3,36 & Cukup \\
\hline
\end{tabular}

Sumber : Data primer diolah, 2019

Tabel 7. menunjukkan pernyataan-pernyataan yang diajukan yang berkaitan dengan pemasaran oleh Devin Sky Hotel Seminyak. Secara umum konsumen memiliki penilaian yang baik terhadap pernyataan-pernyataan yang diberikan. Perolehan nilai tertinggi terdapat pada indikator "Rooftop pool" dengan rata-rata 4,12, memiliki arti bahw a sebagian besar pelanggan merasa puas pada fasilitas Rooftop pool di Devin Sky Hotel Seminyak. Rata - rata keseluruhan persepsi responden memperoleh hasil yang tinggi yakni sebesar 3,36. Hal ini menunjukan indikator dalam penyataan tersebut menjaw ab bahwa pelanggan merasakan kualitas pemasaran yang cukup baik dari segi produk (product), Harga (Price), Distribusi (Place), Promosi (Promotion), Personal(People), Bukti Fisik (Physical Evidance), Proses (Process), lingkungan ekstenal mikro dan makro oleh Devin Sky Hotel Seminyak.

\section{Analisis Kekuatan, Kelemahan, Peluang dan Ancaman (SWOT) Kekuatan (Strengths)}

Berdasarkan 30 indikator yang digunakan untuk mengukur kualitas pemasaran Devin Sky Hotel Seminyak, terdapat 13 indikator yang berpotensi sebagai kekuatan pemasaran, yaitu terdiri dari :

\section{Penempatan bangunan yang strategis \& private}

Posisi bangunan hotel yang berada pada lokasi yang tepat berada dijantung kawasan pariw isata Seminyak merupakan salah satu kekuatan yang bis a digunakan untuk memperkuat daya saing hotel dalam mejual produk. Wisataw an akan lebih mudah untuk mencari lokasi hotel karena terletak tidak jauh dari jalan utama.

2. Wisataw an muda \& lifestyle

Sasaran pasar Devin Sky Seminyak sejauh ini lebih ke arah wisataw an yang rentang umurnya masih tergolong muda dan lebih ke arah wisatawan lifestyle agar sesuai dengan konsep hotel yang modern dan stylish.

3. Segmentasi wisataw an Australia \& Eropa

Wisataw an Australia \& Eropa lebih diutamakan oleh menejemen hotel sejauh ini dikarenakan harga jual kamar yang bisa ditawarkan kepada wisatawan tersebut bisa jauh lebih tinggi jika dibandingkan dengan wisatawan domestik, Asia. Hal tersebut juga didukung oleh tinggkat kunjungan wisataw an Australia \& Eropa yang stabil.

\section{Rooftop pool}

Keberadaan rooftop pool merupakan kekuatan utama dari semua produk yang dimiliki oleh Devin Sky Seminyak. Selain itu juga, adanya rooftop pool ini juga merupakan salah satu pembeda dari beberapa kompetitor lainnya yang tidak memiliki rooftop pool sebaik Devin Sky Seminyak.

5. Spa aquatonic

Selain bekerjasama dengan vendor spa dari luar yaitu Dedari Spa, juga terdapat Aquatonic Spa dengan kolam spa yang terbilang besar. Sangat jarang hotel kelas bintang empat memiliki aquatonic spa sebaik Devin Sky Seminyak, terlebih lagi para pesaing. Keberadaan spa ini menambah kekuatan daya jual hotel dikarenakan spa jenis aquatonic masih jarang ditemukan di hotel area seminyak dengn 
bintang empat. Jadi wisataw an bisa menikmati salah satu fasilitas bintang lima di hotel berbintang empat.

6. Staff hotel

Staff hotel yang ramah merupakan salah satu standar yang harus dimiliki oleh setiap penyedia jasa akomodasi terlebih dalam dunia pariwisata. Staff yang ramah dan selalu siap memberikan bantuan akan menambah tingkat kenyamanan wisataw an yang menginap.

7. Kondisi dari produk yg ditawarkan

Produk produk yang ditawarkan oleh Devin Sky Seminyak merupakan produk yang bagus, baik dari segi kualitas kebersihan, layanan, proses yang cepat serta selalu mengedepankan kenyamanan konsumen dalam hal ini adalah wisatawan yang menginap.

8. Pelayanan yang dilakukan karyawan

Standar pelayanan dari staff hotel sudah diatur sesuai standart operational procedure ( SOP ) yang berlaku agar bisa selalu mengedepankan kualitas, kenyamanan dan memenuhi harapan konsumen.

9. Restaurat \& bar

Design interior dan eksterior bangunan restoran dan bar di Devin Sky Seminyak sangat modern dengan sentuhan ukiran tradisional Bali, sehingga sesuai dengan tagline hotel yaitu International standart local flavour.

10. Kualitas produk yg ditawarkan

Kualitas menjadi bagian utama dari semua produk yang dijual. Menjaga kualitas produk agar tidak membuat calon konsumen kecewa terhadap produk produk yang ditawarkan oleh hotel merupakan hal utama. Sejauh ini pihak hotel sudah sangat menjaga kualitas produk yang dijual, agar tidak sedikitpun mengecewakan konsumen.

11. Kamar

Terdapat beberapa tipe kamar yang dijual oleh hotel yaitu superior, deluxe garden, deluxe twin/king, premiere pool, premiere jacuzzi dan penthouse. Tipe kamar yang paling menarik dan juga menjadi handalan hotel adalah tipe deluxe king, premiere pool dan premiere jacuzzi. Selain adanya fasilitas jacuzzi dalam kamar, juga terdapat pilihan kolam renang pribadi, sehingga akan memberikan privasi bagi tamu yang menginap.

12. International standar local flavour

Tagline hotel ini lebih mengarahkan kepada pencitraan hotel yang seluruh standar baik pelayanan, kualitas produk dan semua sistem yang terdapat didalamnya sudah menggunakan standar internasional, namun demikian sentuhan cita rasa tradisional masih kental didalamnya misal dari beberapa ornamen ornamen ukiran, beberapa pilihan menu makanan, spa dan design ruangan.

13. Online promotions

Promosi online dimasukkan kedalam salah satu kemungkinan untuk menjadi kekuatan yang dimiliki Devin Sky Seminyak dikarenakan dalam beberapa promosi online yang dilakukan sesuai dengan target meskipun dengan mengeluarkan biaya tambahan untuk promosi tersebut. Hal ini kedapannya bisa dikembangkan kembali dengan membuat berbagai macam promo yang lebih variatif dan menarik agar calon konsumen tertarik untuk membeli produk yang hotel taw arkan melaluipromo tersebut.

Dari 13 indikator tersebut yang memperoleh penilaian terendah dari responden adalah indikator International standar local flavour dan online promotion. Dimana, indikator International standar local flavour memperoleh nilai rata-rata 3,36 dan indikator online promotion memperoleh nilai rata-rata 3,34. Hal ini menunjukkan masih cukup banyak wisatawan yang merasa bahwa Devin Sky Hotel Seminyakbelum mampu dengan baik menerapkan tagline tersebut pada setiap produkyang ditawarkan oleh pihak hotel. Standar internasional dengan tetap mengusung sentuhan tradisional didalamnya dirasa terlihat belum begitu sesuai dengan keadaan sehari-harinya. Selain itu cukup banyak wisatawan yang merasa bahwa promosi online yang dilakukan oleh Devin Sky Hotel Seminyak kurang maksimal.

Hal tersebut juga sesuai dengan hasil wawancara pada informan hotel yang menyatakan bahwa tagline hotel tersebut memang belum begitu optimal dalam proses penerapanya dikarenakan masih dalam tahap penyesuaian dan perbaikan dalam artian masih mencari apa saja yang sesuai dan 
kurang sesuai dengan tagline tersebut jika diterapkan, sehingga nanti hal yang kurang sesuai bisa untuk dimodifikasi agar bisa sesuai dengan tagline international standart local flavour. Tingkat promosi online yang rendah juga dinyatakan oleh John selaku Ecommerce dan Hendrik Supardi selaku Marcomm Manager hotel yang mengatakan bahwa tingkat promosi online melalui social media masih kurang dikarenakan frekunsi update untuk social media masih jarang. Hal tersebut juga sejalan dengan pembuatan promo-promo hotel yang bisa dikatakan masih sedikit. Penggunaan website masih sangat tidak optimal, hal tersebut dilihat dari tingkat reservasi tamu yang berasal dari website yang rendah. Namun demikian promosi online yang menggunakan B2B seperti Booking.com, Agoda, Expedia dan traveloka bisa dikatakan bagus hal tersebut dibuktikan dari booking engine yang digunakan, Booking.com menempati posisi tertinggi yaitu 40\%, Expedia 30\%, Agoda $20 \%$ dan traveloka $10 \%$.

\section{Kelemahan (Weakness)}

Berdasarkan 30 indikator yang digunakan untuk mengukur kualitas pemasaran De Vins Sky Hotel Seminyak, terdapat 7 indikator yang dapat menjadi faktor kelemahan dalam pemasaran, yaitu terdiri dari :

1. Akses menuju ke hotel

Akses menuju hotel dikatakan sebagai kelemahan diakrenakan oleh beberapa faktor yaitu kondisi jalan paving yang kurang baik, terdapat beberapa lubang serta terdapatnya anjing warga yang berkeliaran di sepanjang jalan tersebut sehingga dikhawatirkan terjadi hal yang tidak diinginkan terjadi kepada wisataw an yang melintas menuju hotel.

2. Meeting room

Keberadaan meeting room di Devin Sky Hotel Seminyak masih kurang mendukung. Ukuran ruangan yang kecil kurang tepat jika digunakan untuk menampung meeting dengan jumlah peserta yang banyak.

\section{Offline promotions}

Promosi secara offline juga masih belum dilakukan secara luas dikarenakan oleh beberapakendala seperti keuangan. Selama ini promosi offline hanya dilakukan di surat kabar/majalah dengan metode pembayaran secara barter.

4. Kenyamanan dalam menggunakan produk

Beberapa alasan yang dijadikan acuan memasukkan tingkat kenyamanan dalam menggunakan produk ke dalam kelemahan adalah terdapat beberapa kali complaint wisatawan yang tersetrum aliran listrik di jacuzzi kamar, complaint terhadap suara musik di rooftop yang terdengar sampai di kamar dan kurangnya fasilitas penyewaan kendaraan bagi tamu.

5. Menjalin kerjasama dengan perusahaan \& pemerintah

Pihak hotel kurang menjalain kerjasama dengan perusahaan dan pemerintahan dikarenakan tidak tersedianya fasilitas ruang meeting yang layak. Berdasarkan pada kenyataan bahwa tidak tersedianya ruang meeting yang memadai di hotel maka sampai saat ini kerjasama dengan perusahaan corporate dan pemerintahan masih dibatasi.

6. Harga produk yang ditawarkan

Jika dibandingkan dengan harga kompetitor, harga jual kamar memang terbilang cukup tinggi sehingga terdapat kemungkinan calon koncumen lebih memilih hotel dengan harga yang lebih murah.

7. Manfaat produk

Manfaat yang didapat oleh wisatawan yang menginap memang menjadi prioritas utama bagi perusahaan. Namun beberapa hal penunjang masih belum mendukung secara penuh terhadap hal tersebut seperti kurangnya fasilitas penyew aan kendaraan bagi wisataw an.

Dari 7 indikator tersebut yang memperoleh penilaian terendah dari responden adalah indikator manfaat produk dengan nilai rata-rata sebesar 3,13. Hal ini menunjukkan bahwa cukup banyak pelanggan yang merasa kurang mendapat manfaat produk dari Devin Sky Hotel Seminyak karena terbatasnya kendaraan/alat transportasi untuk fasilitas tour, mengingat banyaknya kebutuhan berwisata sehingga perlu pengembangan yang disesuaikan dengan kebutuhan tamu. Selain itu, responden merasa bahwa harga produk yang ditaw arkan kurang bersaing dan kurang intens dalam 
melakukan promosi secara offline dan fasilitas meeting room yang dimilai masih kurang memuaskan oleh pelanggan.

Hasil tersebut juga dibenarkan oleh Dona Andilolo selaku Directure Sales \& Marketing Devin Sky Hotel Seminyak yang menyatakan bahw a ketersediaan pelayanan antar jemput untuk wisatawan masih kurang. Saat ini hanya ada antar gratis sampai Seminyak Market dan itupun hanya 2 kali dalam sehari, pukul 8 pagi dan 3 sore. Airport transfer tersedia namun berbayar dan ada juga yang sudah termasuk dalam harga kamar yang dipesan. Ketersediaan penyewaan sepeda motor juga masih kurang, saat ini yang menyewakan sepeda motor dihotel hanya security hotel dengan jumlah motor yang disewakan hanya 2-3 motor saja. Hal tersebut masih kurang dari cukup jika dilihat dari permintaan tamu setiap harinya. Kemudian ketersediaan fasilitas meeting yang minim, hal tersebut dikarenakan hotel tidak memiliki meeting room yang besar, hanya tersedia ruang bussines center yang tidak mampu menampung jumlah orang yang banyak ketika meeting. Sehingga fasilitas meeting memang tidak dikembangkan. Hal tersebutlah yang menjadi alasan hotel tidak banyak dalam menjalain hubungan pemerintahan maupun perusahaan, dikarenakan hampir sebagian besar tamu pemerintahan ataupun perusahaan corporate yang biasanya memerlukan hotel yang memiliki fasilitas meeting yang memadai. Akses menuju hotel yang kurang dikarenakan jalan yang sedikit bergelombang dan kadang banyak kawana anjing berkeliaran disepanjang jalan. Hal tersebut ditakutkan akan melukai wisataw an jika diserang oleh kaw anan anjing tersebut. Promosi offlineyang masih rendah dikarenakan hotel sangat membatasi tamu group dari travel agent offline, yang berdasarkan penglaman tamu group biasanya akan membuat kegaduhan sehingga akan mengganggu ketenangan dan kenyamanan hotel.

\section{Peluang (Opportunities)}

Berdasarkan 30 indikator yang digunakan untuk mengukur kualitas pemasaran, terdapat 6 indikator yang dapat menjadi peluang bagi pemasaran Devin Sky Hotel Seminyak, yaitu terdiri dari 1. Peningkatan jumlah kunjungan wisataw an

Peningkatan jumlah kunjungan wisataw an dari tahun ke tahun menjadi peluang tersendiri bagi para pelaku penyedia jasa akomodasi pariwisata. Tingkat mobilitas yang meningkat juga merupakan sebuah peluang kedepannya untuk perkembangan bisnis dalam usaha perhotelan.

2. Situasi budaya

Tidak dipungkiri lagi bahwa kearifan lokal daerah Bali menjadi daya tarik utama bagi para wisataw an ayng berkunjung. Terjaganya budaya asli Bali yang masih bisa tetap ada hingga saat ini menjadi peluang yang besar untuk meningkatkan minat wisatawan berkungjung ke Pulau Bali pada khususnya.

3. Kemajuan teknologi

Semakin pesatnya perkembangan teknologi dari masa ke masa merupakan sebuah peluang bagi dunia pariwisata terutama untuk bidang promosi. Semakin mudah dan murahnya teknologi kedepan tentu akan memberikan kemudahan baik bagi wisatawan maupun perusahaan dalam mengakses informasi.

4. Pertumbuhan ekonomi dunia

Pertumbuhan ekonomi yang baik kedepannya, akan menjadi faktor pendukung orang untuk melakukan perjalanan/wisata menuju negara lain sehingga kedepan hal ini akan menjadi peluang yang baik untuk perkembangan pariwisata.

5. Kekuatan travel agent dalam mendatangkan tamu

Menjalin kerjasama yang baik dengan travel agent kedepannya menjadi salah satu aset yang bisa di gunakan untuk menjaga umah tamu yang menginap, terlebih dengan travel agent offline. Semakin baik hotel menjaga hubungan maka kemungkinan untuk reservasi tamu dari agent tersebut akan lebih tinggi.

6. Stuasi politik dalam negeri

Situasi politik dalam negeri akhir akhir ini memang sedang bergejolak, terlebih pada masa pemilu beberapa waktu lalu. Namun arah perkemabangan politik yang semakin kondusif kedepannya tentu menjadi pendukung dalam terjaganya siatu dalam negeri demi kelancaran kegiatan pariwisata.

Dari 6 indikator tersebut yang memperoleh penilaian tertinggi dari responden adalah indikator Peningkatan jumlah kunjungan wisatawan dengan nilai rata-rata sebesar 3,28. Hal ini menunjukkan 
bahwa tingkat kunjungan wisataw an yang tinggi akan menjadi peluang dimasa mendatang. Tingkat kunjungan wisatawan diprediksi akan mengalami peningkatan seiring dengan meningkatnya perekonomian global. Dengan meningkatnya kunjungan wisatawan sangat memungkinkan bagi wisatawan untuk melakukan perjalanan dengan lama tinggal yang lebih panjang. Jadi pada masa mendatang indikator tingkat kunjungan wisatawan yang tinggi masih merupakan peluang..

\section{Ancaman (Threats)}

Berdasarkan 30 indikator yang digunakan untuk mengukur aspek pemasaran, terdapat 4 indikator yang dapat menjadi faktor ancama bagi Devin Sky Hotel Seminyak, yaitu terdiri dari :

1. Potensi masuknya pesaing baru

Potensi masuknya pesaing baru memang tidak dapat dihindari. Semakin tingginya tingkat kunjungan wisatawan maka potensi untuk kembali munculnya pesaing baru dalam jasa akomodasi tentu akan sangat tinggi.

2. Situasi keamanan yang tidak menentu

Tejaminnya kamanan bagi setiap warga negara maupun wisatawan aasinng yang berkujung meruapakan hal utaman yang wajib diberikan oleh sebuah negara. Situasi keamanan memang satu hal yang tidak dapat diprediksi secara tepat. Kondisi keamanan yang berfluktuatif menyebabkan berdampak pada kondisi pariwisata terlebih kepada tingkat kunjungan wisatawan.

3. Persaingan antar hotel

Persaingan memang menjadi ancaman dalam segala bentuk bidang usaha terlebih usaha penyedia jasa akomodasi pariwisata. Namun hal tersebut tidak dapat dihindari dikarenakan sudah merupakan bagian dalam dunia usaha.

4. Daya tawar konsumen

Kemampuan calon konsumen yang semakin jeli melihat unit untuk tempat menginap, bisa dikatakan sebagai ancaman dikarenakan pihak penyedia harus semakin pandai dalam membuat strategi pemasaran agar dapat menarik minat calon konsumen.

Dari 4 indikator tersebut yang memperoleh penilaian tertinggi dari responden adalah indikator persaingan antar hotel dengan nilai rata-rata sebesar 3,07. Hal ini menunjukkan bahwa semakin banyak usaha sejenis hotel seperti Villa-villa, Guest House dan rumah kost bisa memberikan harga yang murah dengan fasilitas sangat lengkap, sehingga tidak menutup kemungkinan wisataw an asing maupun domestik akan memilih tinggal di sejenis hotel tersebut. Hal tersebut tentu menjadi ancama tertinggi bagi Devin Sky Hotel Seminyak, mengingat lokasi hotel berada di kaw as an pariwisata yang memiliki tingkat persaingan hotel yang tinggi. Dona Andilolo menambahkan bahwa persaingan antar hotel memang tidak bisa dihindari mengingat di Bali, Seminyak pada khususnya usaha akomodasi seperti hotel merupakan usaha yang bisa dikatakan utama melihat seminyak meruapakan daerah destinasi wisata yang sangat banyak dikunjungi oleh wisataw an untuk menginap selama berada di Bali. Potensi masuknya pesaing baru sudah dipastikan untuk kedepan akan ada pesaing baru. Namun yang akan dilakukan oleh pihak management hotel adalah meningkatkan kualitas produk yang dijual, serta perbaikan pada beberapa indicator yang masih kurang optimal untuk dapat memenangkan persaingan dalam mendapatkan tamu serta tingkat hunian kamar kedepannya. 
Tabel 8 Matrik SWOT Strategi Pemas aran Devin Sky Hotel Seminyak

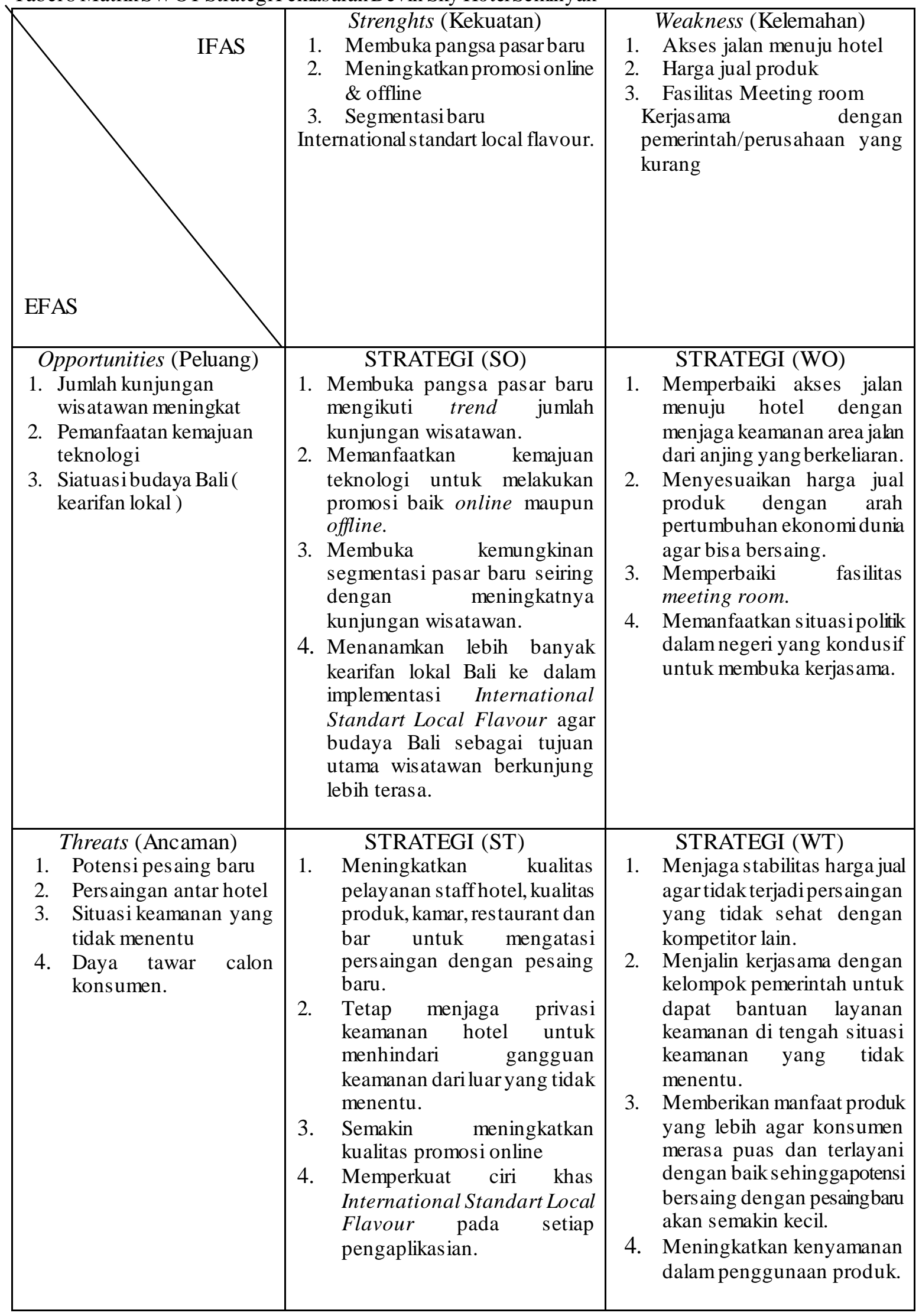

Berdasarkan hasil matriks SWOT pada Tabel 3.10, maka dapat diketahui pihak manajemen dapat mengembangkan Devin Sky Hotel Seminyak dengan beberapa strategi sebagai berikut: 


\section{Strategi SO}

1. Membuka pangsa pasar baru mengikuti trend jumlah kunjungan wisatawan.

2. Memanfaatkan kemajuan teknologi untuk melakukan promosi baik online maupun offline.

3. Membuka kemungkinan segmentasi pasar baru seiring dengan meningkatnya kunjungan wisataw an.

4. Menanamkan lebih banyak kearifan lokal Bali ke dalam implementasi International Standart Local Flavour agar budaya Bali sebagai tujuan utama wisataw an berkunjung lebih terasa.

\section{Strategi WO}

1. Memperbaiki akses jalan menuju hotel dengan menjaga keamanan area jalan dari anjing yang berkeliaran.

2. Menyesuaikan harga jual produk dengan arah pertumbuhan ekonomi dunia agar bisa bersaing.

3. Memperbaiki fasilitas meeting room untuk dapat menarik calon wisatawan/menjalin kerjasama dengan pemerintahan dan perusahaan yang biasanya memerlukan fasilitas meeting.

4. Memanfaatkan situasi politik dalam negeri yang kondusif untuk membuka kerjasama dengan pemerintah/perusahaan untuk menarik minat mereka menginap di Devin Sky Hotel Seminyak.

\section{Strategi ST}

1. Meningkatkan kualitas pelayanan staff hotel, kualitas produk, kamar, restaurant dan bar untuk mengatasi persaingan dengan pesaing baru.

2. Tetap menjaga privasi keamanan hotel untuk menhindari gangguan keamanan dari luar yang tidek menentu.

3. Semakin meningkatkan kualitas promosi online baik dari segi konten, design dan harga promo untuk memenangkan taw ar menawar harga dengan calon konsumen.

4. Memperkuat ciri khas International Standart Local Flavour pada setiap pengaplikasian di hotel agar wisataw an memiliki kesan khusus setelah berkunjung ke Devin Sky Hotel Seminyak.

\section{Strategi WT}

1. Menjaga stabilitas harga jual agar tidak terjadi persaingan yang tidak sehat dengan kompetitor lain.

2. Menjalin kerjasama dengan kelompok pemerintah untuk dapat bantuan layanan keamanan di tengah situasi keamanan yang tidak menentu.

3. Memberikan manfaat produk yang lebih agar konsumen merasa puas dan terlayani dengan baik sehingga potensi bersaing dengan pesaing baru akan semakin kecil.

4. Meningkatkan kenyamanan dalam penggunaan produk untuk mengurangi kemampuan daya taw ar calon konsumen.

\section{KESIMPULAN}

Keseluruhan persepsi responden memperoleh hasil yang cukup dengan rata-rata 3,36. Hal ini menunjukan indikator dalam penyataan tersebut menjaw ab bahw a pelanggan merasakan kualitas pemasaran yang cukup baik dari segi produk (product), Harga (Price), Distribusi (Place), Promosi (Promotion), Personal (People), Bukti Fisik (Physical Evidance), Proses (Process), lingkungan ekstenal mikro dan makro oleh Devin Sky Hotel Seminyak. Berdasarkan hasil analisis SWOT, terdapat beberapa strategi yang dapat diterapkan untuk mengembangkan Devin Sky Hotel Seminyak seperti strategi SO yaitu membuka pasr baru mmengikuti trend kunjungan w isataw an, memanfaatkan kemajuan teknologi unutk promosi. Strategi WO dengan memperbaiki kelemahan yang ada seperti jalan menuju hotel, meeting room, menyesuaikan harga jual. Selanjutnya strategi ST yaitu dengan menigkatkan kualitas pelayanan, menjaga privasi tamu dan meningkatkan promosi online. Terakhir dengan strategi WT yaitu menjaga stabilitas harga, menjalin kerjasama dengan pemerintah serta memberikan kenyamanan dan manfaat produk kepada tamu yang menginap.

\section{Ucapan Terima kasih}

Kami menyampaikan ucapan terima kasih kepada Dekan Fakultas Pariwisata Universitas Udayana yang telah memberikan dukungan sehingga kegiatan Laporan Akhir ini bisa berjalan. Terima kasih juga kami sampaikan kepada Ketua Program Studi Diploma IV Pariwisata Fakultas 
Pariwisata atas fasilitas dan dukungan yang telah diberikan. Terima kasih juga saya sampaikan kepada kedua pembimbing penulis yang telah membimbing dan mengarahkan penulis dalam menyelesaikan jurnal. Terima kasih juga kepada Ownner, General Manager, Hrd, Dosm, Sales Marketing team dan seluruh karyaw an Devin Sky Hotel Seminyak yang telah meluangkan w aktunya untuk memberikan informasi dan masukan serta data yang diperlukan dalam penelitian ini, serta semua pihak yang tidak dapat penulis sebutkan satu persatu yang telah banyak membantu hingga terselesaikannya penelitian ini.

\section{DAFTAR PUSTAKA}

Azwar (dalam Margaretha dan Edwin. 2012). Pengertian Definisi Operasional Variabel. 2012

Rai Utama. 2013. Strategi Menuju Pariwisata Bali yang Berkualitas Pendahuluan. Journal of Bali Studies, Vol. 3, No. 2

Durianto, Sugiarto, Widjaja dan Supratikno, 2003. Inovasi Pasar dengan Iklan yang Efektif. Jakarta: PT. Gramedia Pustaka Utama.

Erika Desy, 2015. Fakultas Ilmu Administrasi Universitas Brawijaya. Penentuan strategi bisnis manajemen hotel dalam menghadapi persaingan (Studi Kasus di Quds Royal Hotel Surabaya).

Husein Umar, 2002, Riset Pemasaran dan Perilaku Konsumen, Jakarta : Gramedia Pustaka Utama

Freddy Rangkuti, 2002. Tentang Matrik Analisis SWOT

J Salusu, 2000, Pengambilan Keputusan Stratejik : untuk Organisasi Publik dan Organisasi Nonprofit, Jakarta : PT. Grasindo

J.HutabaratdanM.Huseini .Pengantar Manajemen Strategik Kontemporer, Strategik di Tengah Operasional / (https://strategika.wordpress.com/2007/06/24/pengertian-strategi/ ) diakses tanggal 15 September 2016

Keputusan Menteri Parpostel no Km 94/HK103/MPPT 1987, Pengertian Hotel

Philip Kotler, 1997, Marketing Management (edisi terjemahan), New Jersey : Prentice-Hall

Putra, ADI, 2013, Strategi Pemasaran Produk MICE di Patra Jasa Bali Resort Villas, Fakultas Pariwisata Universitas Udayana.

Sarwono, J. 2006. Metode Penelitian Kuantitatif dan Kualitatif. Yogyakarta : Graha Ilmu

Seminyak, De Vins Sky Hotel Seminyak. 2016. Hotel Devin Sky Hotel Seminyak. Dengan alamat situs http://www.devinskyhotel.com/id. Diakses pada tanggal 4 mei 2016

Sugiyono.2013. Metodologi Penelitian. Bandung, Alfabeta

Suwarsono, 1998, Manajemen Strategik : Konsep dan Kasus, Yogyakarta :UPP AMP YKPN

Tempo.com dengan alamat situs http://travel.tempo.co/read/news/2013/04/14/199473300/pertumbuhan-hotel-di-balitidak-merata. Diakses pada tanggal 10 Februari 2016 
Viva News dengan situs http://bisnis.news.viva.co.id/new s/read/541617-ini-penyebab-hotel-dibali-perang-tarif. Diakses pada tanggal 10 Februari 2016

Wibisono, 2010, Penerapan Analisis SWOT di The Patra Bali Resort.

http://perilakuorganisasi.com/kenichi-ohmae.html diakses tanggal 15 September 2016

http://elib.unikom.ac.id/files/disk1/699/jbptunikompp-gdl-benazirwal-34906-7-unikom_b2.pdf diakses tanggal 17 September 2016

https://ditarts.wordpress.com/2011/04/27/strategi-generik-michael-porter/ diakses padatanggal 17 September 2016

http://mrasyidin.blogspot.co.id/2010/02/generic.html diakses pada Tanggal 17 September 2016

http://balitribune.co.id/content/heboh-pencabutan-se-moratorium-hotel-disesalkan-dew angubernur-membantah diakses tanggal 10 Oktober 2016

http://w w w .antarabali.com/berita/88927/pemprov-bali-tak-cabut-moratorium-pembangunanhotel diakses pada tanggal 10 Oktober 2016 